\title{
Novel nonsense mutation of BRCA2 gene in a Moroccan man with familial breast cancer
}

\author{
Soukaina Guaoua ${ }^{12}$, Ilham Ratbi ${ }^{1}$, Jaber Lyahyai ${ }^{1}$, Siham Chafai El Alaoui ${ }^{2}$, Fatima-Zahra Laarabi ${ }^{2}$, Abdelaziz Sefiani ${ }^{12}$
}

1. Centre de génomique humaine, Faculté de médecine et de pharmacie, Université

Mohammed V Souissi, Rabat, Morocco

2. Département de génétique médicale, Institut National d’Hygiène, Rabat, Morocco

\begin{abstract}
Background: Breast cancer is the most common cancer in women worldwide. About 5 to $10 \%$ of cases are due to an inherited predisposition in two major genes, $B R C A 1$ and $B R C A 2$, transmitted as an autosomal dominant form. Male breast cancer is rare and is mainly due to $B R C A 2$ than $B R C A 1$ germline mutations.

Objective: Molecular study of $B R C A 2$ gene in man with familial breast cancer.

Methods: PCR and direct sequencing of $B R C A 2$ gene.

Results: Identification of novel heterozygous germline mutation c.6428C $>$ A ; p.Ser2143Stop of BRCA2 gene.

Keywords: male, breast cancer, BRCA2 gene, mutation, genetic counseling.

African Health Sciences 2014; 14(2):468-471
\end{abstract}

DOI: http://dx.doi.org/10.4314/ahs.v14i2.25

\section{Introduction}

Breast cancer is the most common cancer among women, accounting for about $30 \%$ of all cancers [1]. The majority are sporadic, where as 5 to $10 \%$ are due to an inherited predisposition to breast and ovarian cancers, transmitted as an autosomal dominant form with incomplete penetrance [2,3]. Germline mutations of $B R C A 1$ and $B R C A 2$ genes are involved in nearly $10 \%$ of ovarian cancers and $3-5 \%$ of breast cancers respectively $[4,5]$. The two genes belong to a class of tumor suppressor genes that maintain genomic integrity to prevent uncontrolled proliferation of tumor cells. They are also involved in DNA damage recognition, double-strand break repair, checkpoint control, transcription regulation and chromatin remodeling [6]. $B R C A 1$ and $B R C A 2$ are large genes containing 5,592 and 11,385 nucleotides spread over approximately 100,000 bases of genomic DNA each [7]. More than 1880 BRCA mutations are reported [8]. These mutations are distributed throughout the coding region and flanking intronic sequences, most are framshifts causing

\section{Corresponding author: \\ Soukaina Guaoua \\ Département de génétique médicale Institut National d'Hygiène, Avenue Ibn Batouta, B.P. 769 Rabat - Morocco. \\ Tel. +212 (0) 675283238 . \\ Fax.+212(0) 537772067. \\ E-mail:soukainaguaoua@gmail.com}

a frameshift reading of nonsense mutations or splice site alterations that lead to truncated proteins [9]. Breast cancer is a very rare disease in men, accounting for less than $1 \%$ of all cancers [10]. BRCA2 mutations account for a significant proportion in both man breast cancer cases with or without a family history of the disease $[11,12]$.

We report here a novel nonsense mutation of $B R C A 2$ gene in a Moroccan man with breast cancer and family history of the disease.

\section{Case report}

A 63 years-old man with breast cancer was referred for genetic counselling. The family had five other women with breast cancer, and three cases with prostate, liver and uterus cancers (Figure 1).

One year before, he was diagnosed with infiltrating ductal carcinoma grade 2 of $18 \mathrm{~mm}$ diameter in his left breast. Hercept test (HER2) was negative, oestrogen and progesterone receptors were positive. The patient had no other associated diseases. Conservative tumorectomy was performed. He was treated by chemotherapy and local radiotherapy. Written informed consent was obtained from the patient prior to implementation of the genetic study reported here.

Genomic DNA was extracted from peripheral blood lymphocytes using salt extraction methods [13]. We chose to analyse firstly the exon 11 of $B R C A 2$ gene by bi-directional sequencing, because it's the longest exon with the most reported mutations BIC (Breast Cancer Information Core): http://research.nhgri.nih. gov/bic/. Sequence variation was verified in a new 
blood sample. The BRCA2 mutation was numbered according to GenBank accession number NM_000059, in which A in the AUG start codon has number 229. In silico prediction of the functional consequence of the nonsens variant was performed using, MutationTaster (http://www.mutationtaster.org/) [14] and SIFT (Sorting Intolerant From Tolerant): http:/ /blocks.fhcrc. org/sift/SIFT. html [15].

Figure 1: Family pedigree. Breast (BC), uterus (UC), prostate (PC) and liver (LC) cancers are indicated as well as the age at diagnosis. Diagonal slash indicates deceased, while the proband is indicated with an arrow.

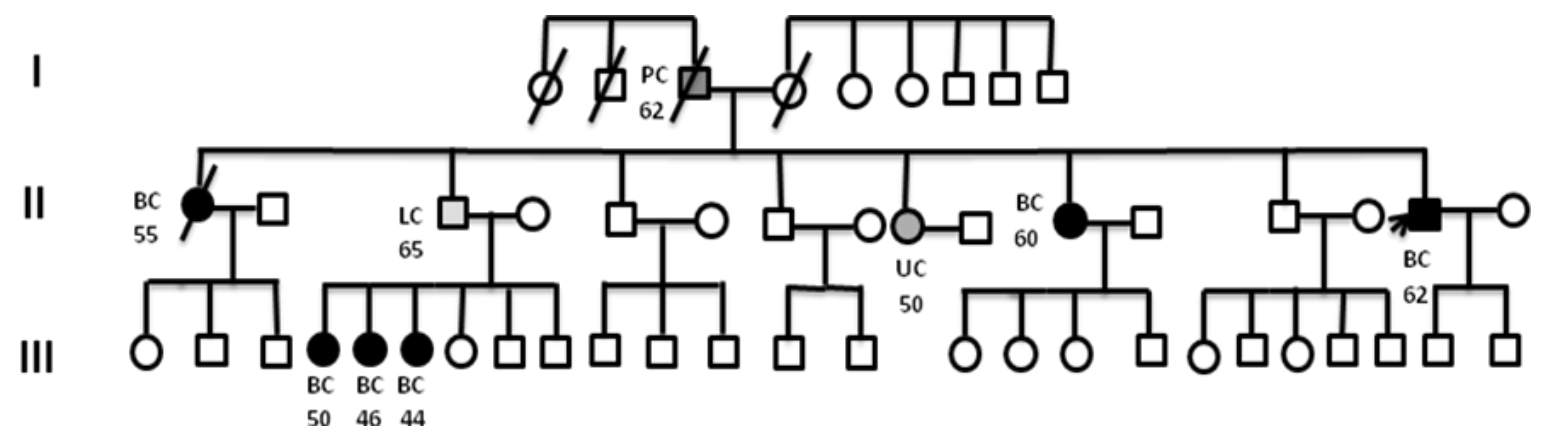

\section{Results and discussion}

Molecular analysis in the patientidentified a heterozygous BRCA2 nucleotide mutation c.6428 C>A in exon 11. This variation introduces a nonsense mutation changing amino acid 2143 from serin to stop codon (Figure 2).

To our best knowledge, this mutation was never reported before in the Breast Cancer information Core database (BIC; http://research.nhgri.nih.gov/bic/), or other resources. The two protein prediction programmes used to predict the functional consequence of the BRCA2 p.Ser2143Stop mutation estimated it to be pathogenic $[14,15]$.

Hereditary breast and ovarian cancer syndrome is an autosomal dominant inherited cancer-susceptibility syndrome. This syndrome is characterised by multiple family members with breast or ovarian cancer or both, the presence of both breast and ovarian cancer in a single individual, and early age of breast cancer onset [16]. Approximately $10 \%$ of cases of ovarian cancer and $3-5 \%$ of cases of breast cancer are known to be associated with germline mutations in BRCA1 and $B R C A 2[4,5]$. Male breast cancer is rare, with the peak age of onset at 71 years. BRCA2 mutations are more frequent than BRCA1 with $15-20 \%$ of cases giving a family history [17]. A male BRCA2 carrier has a $6 \%$ lifetime risk of developing the disease, compared with $0.1 \%$ in the normal population [18].

Recently in Morocco, our group and others local genetic centers, have developed oncogenetic consultation for familial forms of breast and ovarian cancers. These centers offer currently genetic testing for $B R C A 1$ and $B R C A 2$ genes, and mutational profile of these genes is becoming better known in Moroccan population $[19,20]$. Even more, recently some healthy Moroccan females with a high risk of developing breast cancer benefited from presymptomatic diagnosis for a preventive management [19]. In morocco, there is a national program against cancer that does not include actually a national genetic counseling and testing program for the familial mutations and polymorphisms which are common among the Moroccan population.

In this study, we have identified a novel nonsense germline mutation of $B R C A 2$ gene in a man with breast cancer and family history. This mutation is considered to be deleterious using in silico analysis. In practice for this family, we are enabled to offer a genetic councelling and to conduct DNA testing for presymptomatic diagnosis in healthy major men and women at risk if they will request it. This will allow us to introduce supervision of asymptomatic carriers in order to prevent and early diagnosis breast cancer in this family. More generally, the identification of this new mutation will allow to enrich the Moroccan Human Mutation Database that lists mutations reported in the Moroccan population (MoHuMuDa; http://www.sante.gov.ma/Departements/ $\mathrm{INH} / \mathrm{MoHuMuDa} /$ index.htm). This database was build up in 2007, and is devoted to the collection of reported human mutations in Mendelian diseases identified in the native Moroccan population, or in patients from Moroccan origin living abroad. For each mutation disease, a specific table precise the name of the gene, 
Figure 2: Electrophregram showing normal sequence (a) and the heterozygous c.6428 C>A of BRCA2 gene causing the p.Ser2143Stop amino acid change (b).

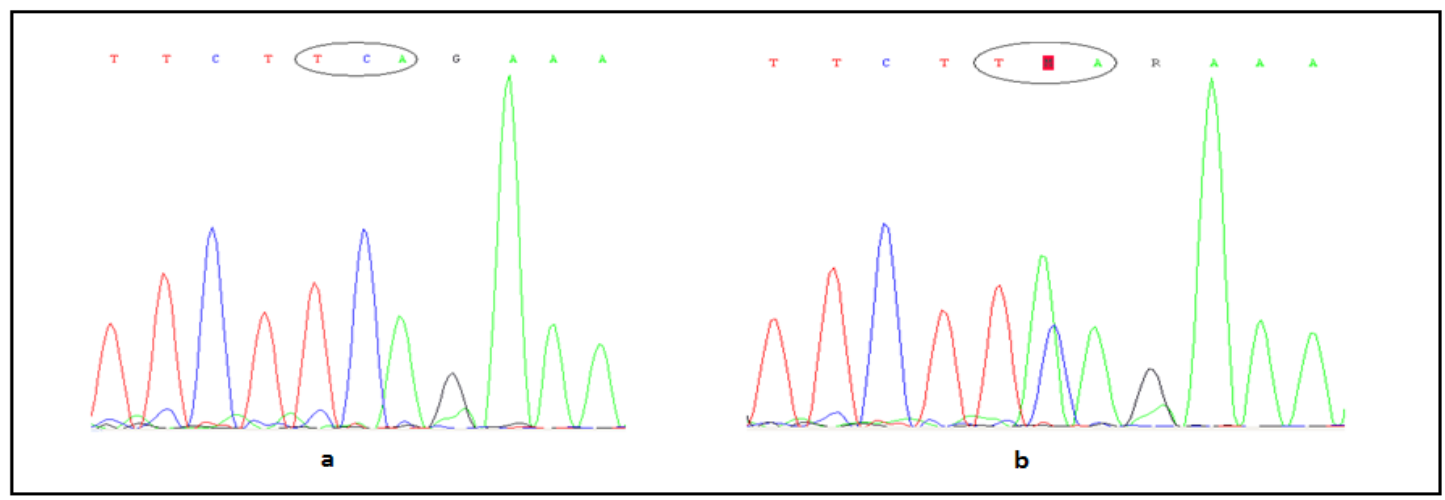

the OMIM number of the disease, the published DNA, and amino-acid change, the proper nomenclature, the number of chromosomes, the frequency of the mutation, and the source of the data [21].

Theses mutations data could help, if recurrent mutations in Moroccan patients are identified, to establish low cost public health strategies for molecular diagnosis of patients with hereditary breast cancer. The beneficial impact on the care and counseling of individuals at risk is major, in order to reduce breast cancer mortality. In summary, we here report a novel nonsense mutation of BRCA2 gene in Moroccan case of a man with familial breast cancer. Genetic screening is now offered to all family members.

\section{Acknowledgments}

The authors thank all the staff of the Department of Medical Genetics of the National Institute of Health for their support.

\section{References}

1. Willems PG. Susceptibility genes in breast cancer: more is less? Clin Genet. 2007; 72: 493-496.

2. Lynch, H.T., W.A. Albano, B.S. Danes, et al. Genetic predisposition to breast cancer. Cancer 1984; 53(3 Suppl): p. 612-22.

3. Claus, E.B., J.M. Schildkraut, W.D. Thompson, and N.J. Risch, The genetic attributable risk of breast and ovarian cancer. Cancer 1996; 77(11): p. 2318-24.

4. Robson ME, Boyd J, BorgenPIand Cody HS III: Hereditary breast cancer. CurrProblSurg 2001; 38: 387 480.

5. Risch HA, McLaughlin JR, Cole DE, et al. Population BRCA1 and BRCA2 mutation frequencies and cancer penetrances: a kin-cohort study in Ontario, Canada. $J$
Natl Cancer Inst 2006; 98: 1694-1706.

6. Mohamad HB. Counseling for male BRCA mutation carriers: a review. Apffelstaedt JP Breast 2008; 17: 441450.

7. Filippini S, Blanco A, Fernández-Marmiesse A, et al. Multiplex NaPshot for detection of BRCA1/2 common mutations in Spanish and Spanish related breast/ovarian cancer families. BMC Med Genet 2007; 29: 40.

8. Boeri, L., C. Canzonieri, C. Cagioni, F. Ornati, and C. Danesino, Breast cancer and genetics. Journal of Ultrasound 2011; 14: p. 171-176.

9. Szabo C, Masiello A, Ryan JF, Brody LC. Hum Mutat. 2000; 16(2):123-31.

10. Sasco, A.J., A.B. Lowenfels, and P. Pasker-de Jong, Review article: epidemiology of male breast cancer. A meta-analysis of published case-control studies and discussion of selected aetiological factors .International journal of cancer. Journal international du cancer, 1993; 53(4): p. 538-49.

11. Couch FJ, Farid LM, DeShano ML, et al. BRCA2 germline mutations in male breast cancer cases and breast cancer families. Nature Genet 1996; 13: 123125.

12. Friedman LS, Gayther SA, Kurosaki T, et al. Mutation analysis of BRCA1 and BRCA2 in a male breast cancer population. Am J Hum Genet 1997; 60: 313-319.

13. Sambrook J, Fritsch EF, Maniatis T. Isolation of DNA from mammalian cells. In: Sambrook J, Fritsch EF, Maniatis T, editors. Molecular cloning a laboratory manual. New York:Cold Spring Harbor Laboratory Press; 1989.

14. Schwarz JM, Ro"delsperger C, Schuelke M, Seelow D. MutationTaster evaluates disease-causing potential of sequence alterations. Nat Methods 2010; 7:575-576. 
15. Ng PC, Henikoff S SIFT: predicting amino acid changes that affect protein function. Nucleic Acids Res 2003; 31:3812-3814.

16. ACOG Committee on Practice Bulletins: Hereditary breast and ovarian cancer syndrome. Gynecol Oncol 2009; 113: 6-11.

17. Basham VM, Lipscombe JM, Ward JM et al BRCA1 and BRCA2 mutations in a population-based study of male breast cancer. Breast Cancer Res 2002; 41 R2.

18. Friedman LS, Gayther SA, Kurosaki T et al Mutation analysis of BRCA1 and BRCA2 mutations in a male breast cancer population. Am J Hum Genet
1997; 60 313-9.

19. Laarabi, F.Z., I.C. Jaouad, K. Ouldim. Genetic testing and first presymptomatic diagnosis in Moroccan families at high risk for breast/ovarian cancer. Oncology letters 2011; 2(2): p. 389-393.

20. Tazzite, A., H. Jouhadi, S. Nadifi, et al. BRCA1 and BRCA2 germline mutations in Moroccan breast/ovarian cancer families: novel mutations and unclassified variants. Gynecologic oncology 2012; 125(3): p. 687-92.

21. Ratbi I, Gati AE, Sefiani A. The Moroccan human mutation database. Indian J Hum Genet. 2008 Sep;14(3):106-7. 